\title{
Elevated Levels of Endothelial Cell-Derived Microparticles following Short-Term Withdrawal of Continuous Positive Airway Pressure in Patients with Obstructive Sleep Apnea: Data from a Randomized Controlled Trial
}

\author{
Lisa Ayers ${ }^{a}$ Anne-Christin Stoewhas ${ }^{c}$ Berne Ferry ${ }^{a}$ John Stradling ${ }^{b}$ \\ Malcolm Kohler ${ }^{c, d}$ \\ a Department of Clinical Immunology and ' Sleep Unit, Oxford Centre for Respiratory Medicine, Churchill Hospital, \\ Oxford, UK; ' CSleep Disorders Centre and Pulmonary Division, University Hospital Zurich, and ${ }^{\mathrm{d}}$ Centre for Integrative \\ Human Physiology, University of Zurich, Zurich, Switzerland
}

\section{Key Words}

Obstructive sleep apnea $\cdot$ Continuous positive airway pressure $\cdot$ Endothelial dysfunction $\cdot$ Cell-derived microparticles

\section{Abstract \\ Background: Obstructive sleep apnea has been associated with impaired endothelial function; however, the mecha- nisms underlying this association are not completely under- stood. Cell-derived microparticles may provide a link be- tween obstructive sleep apnea and endothelial dysfunction. Objectives: This randomized controlled trial aimed to exam- ine the effect of a 2-week withdrawal of continuous positive airway pressure (CPAP) therapy on levels of circulating mi- croparticles. Methods: Forty-one obstructive sleep apnea patients established on CPAP treatment were randomized to either CPAP withdrawal (subtherapeutic CPAP) or continuing therapeutic CPAP, for 2 weeks. Polysomnography was per- formed and circulating levels of microparticles were ana- lyzed by flow cytometry at baseline and 2 weeks. Results: CPAP withdrawal led to a recurrence of obstructive sleep ap- nea. Levels of CD62E+ endothelium-derived microparticles}

increased significantly in the CPAP withdrawal group compared to the continuing therapeutic CPAP group (median difference in change +32.4 per $\mu \mathrm{l} ; 95 \% \mathrm{Cl}+7.3$ to +64.1 per $\mu \mathrm{l}, \mathrm{p}=0.010)$. CPAP withdrawal was not associated with a statistically significant increase in granulocyte, leukocyte, and platelet-derived microparticles when compared with therapeutic CPAP. Conclusions: Short-term withdrawal of CPAP therapy leads to a significant increase in endotheliumderived microparticles, suggesting that microparticle formation may be causally linked to obstructive sleep apnea and may promote endothelial activation.

Copyright $\odot 2012$ S. Karger AG, Basel

\section{Introduction}

Obstructive sleep apnea (OSA) is characterized by repetitive apneas/hypopneas during sleep, associated with oxygen desaturations and arousals from sleep. It has been estimated that between 2 and $4 \%$ of the adult population in Western countries suffers from symptomatic OSA syndrome (OSAS), and it is becoming more prevalent as the average population body weight rises [1]. OSAS can be ef-

\section{KARGER}

E-Mail karger@karger.com

www.karger.com/res
(C) $2012 \mathrm{~S}$. Karger AG, Basel

0025-7931/13/0856-0478\$38.00/0
Lisa Ayers

Oxford University Hospitals NHS Trust

Department of Clinical Immunology, Churchill Hospital

Oxford OX3 7LJ (UK)

E-Maillisa.ayers@nhs.net 
fectively treated with continuous positive airway pressure (CPAP).

OSAS is associated with daytime sleepiness and increased risk of traffic accidents [2]. Cross-sectional and prospective studies have implicated OSA as an important causal factor in cardiovascular disease [3-6]. The link between OSA and cardiovascular disease is not fully understood; however, it is thought that the physiological consequences of OSA, including intermittent hypoxia and intrathoracic pressure changes and arousals, can all result in endothelial dysfunction and ultimately arterial disease [7]. Endothelial dysfunction has been shown to improve following CPAP therapy [8-10]. Despite the physiological benefits achieved by CPAP therapy, adherence can be poor, with many patients choosing to withdraw from treatment due to side effects, problems with the device, or no perceived benefit [11].

Circulating cell-derived microparticles (MPs) originate from the plasma membrane of activated or apoptotic cells, including platelets, leukocytes, and endothelial cells. Although once thought to be inert cellular dust, they are now understood to be involved in the pathogenesis of vascular inflammation, thrombosis, and endothelial dysfunction, all important processes in cardiovascular disease [12]. MPs are elevated in patients with cardiovascular risk factors, and they have been shown to predict subclinical atherosclerosis in asymptomatic patients [13].

There is preliminary data from case-control studies that MP levels are increased in patients with OSA, and that CPAP therapy may lower these levels [14-17]. However, there is no data from randomized controlled trials proving a causal relationship between OSA and increased levels of MPs. We hypothesize that withdrawal from CPAP therapy may lead to an increase in MP levels. We have taken advantage of a novel CPAP withdrawal randomized controlled study investigating the effects of a return of OSA on various outcomes [18] to explore the effects of CPAP on MP levels.

\section{Methods and Materials}

\section{Patients and Study Design}

Patients previously diagnosed with OSAS and treated with CPAP who were registered in a database of the Sleep Disorders Centre and Pulmonary Division of the University Hospital of $\mathrm{Zu}$ rich, Switzerland, were eligible for the trial if they were aged between 20 and 75 years, had an oxygen desaturation index (ODI, $\geq 4 \%$ dips) of more than $10 / \mathrm{h}$ in their initial sleep study, had an ODI $>10 /$ h currently during an ambulatory nocturnal pulse oximetry study (Pulsox-300i; Minolta, Osaka, Japan) performed at the end of a 4-night period without CPAP, and if they had been treated with CPAP for more than 12 months with a minimal average compliance of $4 \mathrm{~h}$ per night.

Patients previously diagnosed with ventilatory failure, CheyneStokes breathing, unstable and untreated coronary or peripheral artery disease, severe and inadequately controlled arterial hypertension, or a history of any sleep-related accident or who were current professional drivers were excluded from the study. The trial was approved by the University Hospital of Zurich research ethics committee (EK-1600) and registered (www.controlled-trials.com, ISRCTN 93153804). Written informed consent was obtained from all participants. The full methods and the results on the primary outcomes (measures of sleep-disordered breathing) and on some of the secondary outcomes (such as sleepiness, blood pressure, heart rate, endothelial function, and markers of inflammation and metabolism) have been described elsewhere [18].

After confirming the persistence of OSA by home overnight pulse oximetry on the last night of a 4-night period without CPAP, eligible patients returned to therapy with CPAP for at least 1 week. After a baseline sleep study on CPAP, patients were randomized in a double blind fashion to either continue with CPAP therapy or switch to subtherapeutic CPAP for 2 weeks. Follow-up sleep studies were performed at 2 weeks.

\section{Sleep Studies and CPAP}

Attended polysomnographic sleep studies were performed and analyzed according to standard methods. Apnea were defined as a reduction in the amplitude of chest wall motion by $>90 \%$ from baseline over the previous $2 \mathrm{~min}$ for $>10 \mathrm{~s}$, and hypopnea were defined as a reduction in the amplitude of chest wall motion by $>50 \%$ from baseline over the previous $2 \mathrm{~min}$ for $>10 \mathrm{~s}$, associated with a $\geq 4 \%$ drop in oxygen saturation [4]. In patients randomized to subtherapeutic CPAP, the subtherapeutic pressure was achieved by setting the CPAP machine to the lowest pressure, inserting a flow-restricting connector at the machine outlet, and inserting 6 extra holes in the collar of the main tubing at the end of the mask to allow air escape and to prevent rebreathing of carbon dioxide as previously described [19]. Sleepiness was assessed using the Epworth sleepiness score (ESS) [20].

\section{Measurement of MPs}

MPs were measured as previously described [14]. Briefly, blood was drawn from fasting participants in the morning between 9:00 and 10:00 am. Within $1 \mathrm{~min}$ of venepuncture, the tubes were centrifuged at 1,550 $\mathrm{g}$ for $20 \mathrm{~min}$ to produce platelet-poor-plasma (PPP). Two hundred and fifty microliters of PPP were frozen immediately and stored at $-80^{\circ} \mathrm{C}$. The $250 \mu \mathrm{PPP}$ were thawed and then washed twice at $18,000 \mathrm{~g}$ for $30 \mathrm{~min}$.

CD31-phycoerythrin (PE) and CD41-phycoerythrin-Cy5 (PECy5) were used to differentiate between platelet-derived MPs (PMPs) CD31+CD41+ and endothelium-derived MPs (EMPs) CD31+CD41-. CD106-PE-Cy5 and CD62E-PE-Cy5 were also used as markers for EMPs. CD45-allophycocyanin (APC) was used as a marker for leukocyte-derived MPs (LMPs). CD66BFITC was used to stain granulocyte-derived MPs. All antibodies were supplied by BD, Oxford, UK.

Appropriate PE, PE-Cy5, and APC isotypes were used as negative controls. Ten microliters of the sample were incubated with the appropriate MAbs for $30 \mathrm{~min}$ at room temperature, protected from light, followed by the addition of $900 \mu \mathrm{l}$ PBS-Ca. 
Fig. 1. Trial profile.

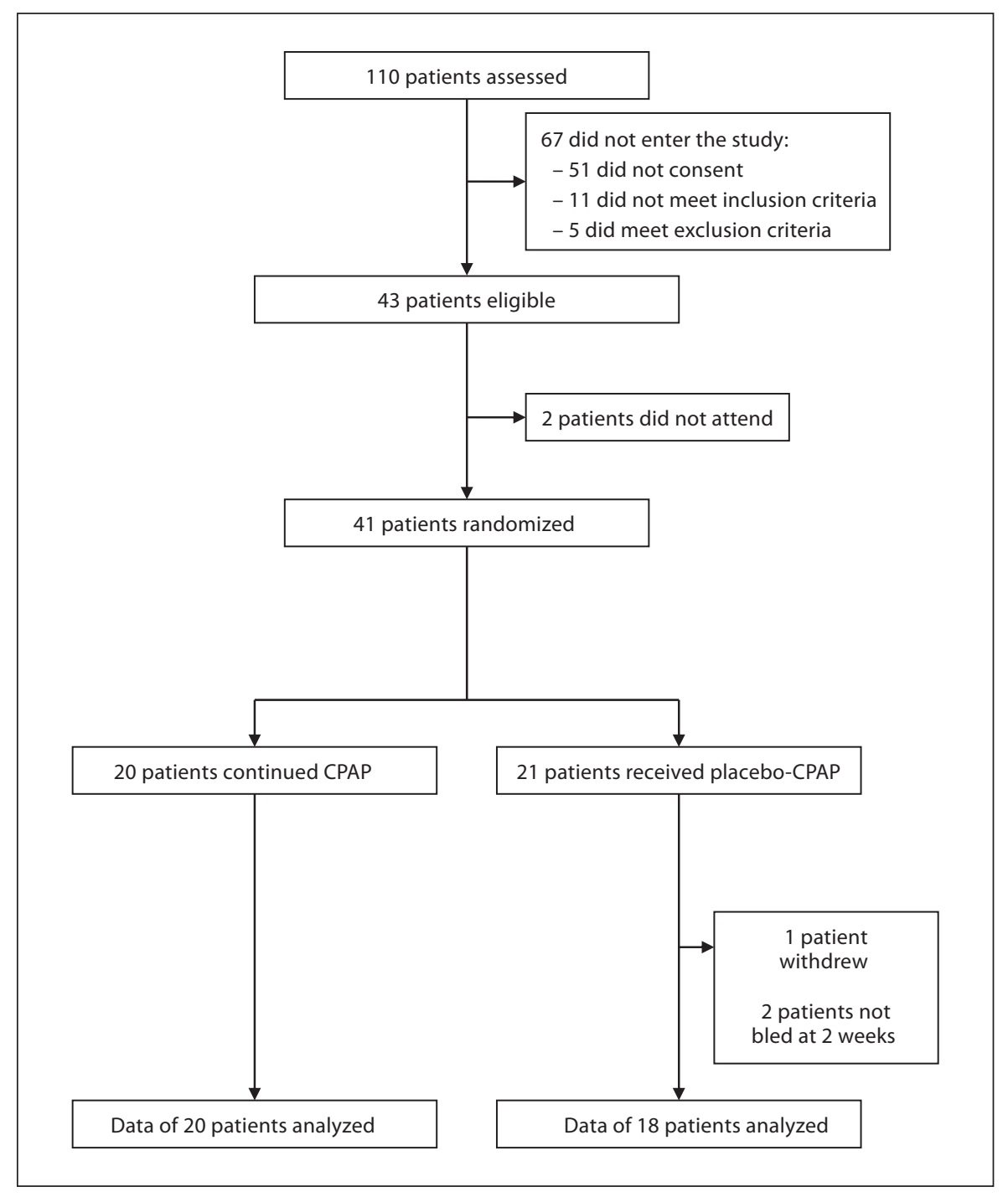

Samples were acquired using a BD FACSCalibur ${ }^{\circledR}$ (Becton Dickinson, Oxford, UK). The MP gate was checked with $1-\mu \mathrm{m}$ beads (Sigma L-2778). The positivity gates were checked by fluorescence-minus-one staining. MP analyses were performed blind to the patient's group allocation.

\section{Data Analysis}

Statistics were performed using GraphPad Prism 4 (GraphPad Software, USA) and SPSS Statistics 19 (IBM Software, USA). Differences in baseline characteristics between groups were assessed by independent $t$ tests and $\chi^{2}$ tests as appropriate. Wilcoxon signed rank tests were performed to assess within-group changes. Comparisons of changes between groups were assessed by MannWhitney $U$ tests. Comparisons of changes between groups, corrected for baseline levels of MPs, were analyzed by analysis of covariance (ANCOVA). Nonparametric confidence intervals were calculated using Confidence Interval Analysis Software (CIA version 1.1). $\mathrm{p}<0.05$ was considered statistically significant.

\section{Results}

\section{Subject Characteristics}

Twenty subjects were randomly assigned to continue on therapeutic CPAP and 21 subjects were randomly assigned to receive subtherapeutic CPAP. One patient in the subtherapeutic CPAP group withdrew from the study 4 days after randomization because of intolerable daytime symptoms. In 2 patients from the subtherapeutic CPAP group, blood could not be drawn at 2 weeks (fig. 1). There were no statistically significant differences in the baseline characteristics of the two groups (table 1). 
Table 1. Baseline patient characteristics

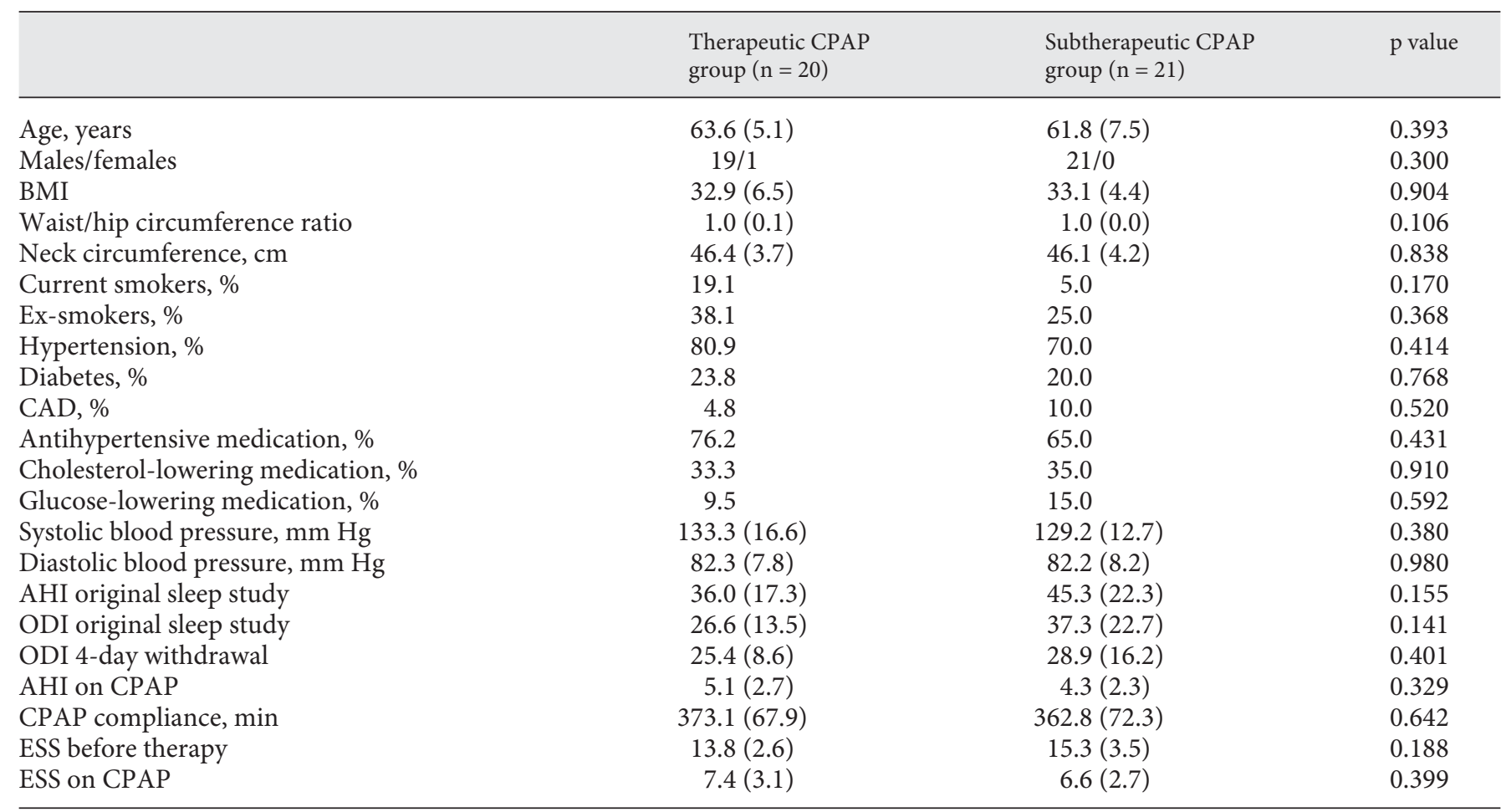

Values are means (SD) where applicable. AHI on CPAP = AHI downloaded from the CPAP machine averaged from the previous 6 months.

Table 2. Effect of CPAP withdrawal on sleep-disordered breathing and sleepiness

\begin{tabular}{|c|c|c|c|c|c|c|}
\hline & \multicolumn{2}{|l|}{ Baseline } & \multicolumn{2}{|c|}{ Change from baseline } & \multirow{2}{*}{$\begin{array}{l}95 \% \mathrm{CI} \\
\text { between groups }\end{array}$} & \multirow[t]{2}{*}{$\mathrm{p}$ value } \\
\hline & $\begin{array}{l}\text { therapeutic } \\
\text { CPAP }(n=20)\end{array}$ & $\begin{array}{l}\text { subtherapeutic } \\
\text { CPAP }(n=21)\end{array}$ & $\begin{array}{l}\text { therapeutic } \\
\text { CPAP }(n=20)\end{array}$ & $\begin{array}{l}\text { subtherapeutic } \\
\text { CPAP }(\mathrm{n}=20)\end{array}$ & & \\
\hline AHI, events/h & $1.7(1.8)$ & $2.2(2.5)$ & $+0.4(2.8)$ & $+33.8(24.3)$ & +22.3 to +44.5 & $<0.001$ \\
\hline ODI, events/h & $0.5(0.8)$ & $0.9(2.0)$ & $-0.2(1.0)$ & $+26.3(22.9)$ & +16.1 to +36.9 & $<0.001$ \\
\hline ESS & $7.4(3.1)$ & $6.6(2.7)$ & $-0.7(2.2)$ & $+2.0(2.7)$ & +1.1 to +4.3 & 0.001 \\
\hline
\end{tabular}

Values are means (SD).

Sleep-Disordered Breathing and Sleepiness

Withdrawal of CPAP significantly increased the apnea/hypopnea index (AHI) at 2 weeks (mean difference in AHI change $+33.5 ; 95 \% \mathrm{CI}+22.3$ to +44.5$)$ and the ODI (mean difference in ODI change +26.4 ; $95 \% \mathrm{CI}+16.1$ to $+36.9)$ in comparison to continuation of CPAP $(p<0.001$ for all comparisons). ESS increased significantly at 2 weeks in the subtherapeutic group compared to the therapeutic group (mean difference in ESS change $+2.7 ; 95 \%$ $\mathrm{CI}+1.1$ to $+4.3, \mathrm{p}=0.001)($ table 2$)$.

\section{Endothelium-Derived MPs}

Withdrawal of CPAP therapy was associated with a significant increase in the number of both CD62E+ EMPs $(\mathrm{p}=0.040)$ and CD106+ EMPs $(\mathrm{p}=0.007)$ not seen in the therapeutic CPAP group (fig. 2, 3). There was a significant difference in the change in CD62E+ EMP levels (median difference in change +32.4 per $\mu \mathrm{l}$; $95 \% \mathrm{CI}+7.3$ to +64.1 per $\mu \mathrm{l}, \mathrm{p}=0.010$ ) (fig. $2 \mathrm{c}$ ) between the therapeutic and subtherapeutic groups, and this level of significance was not altered when a correction for baseline levels of 

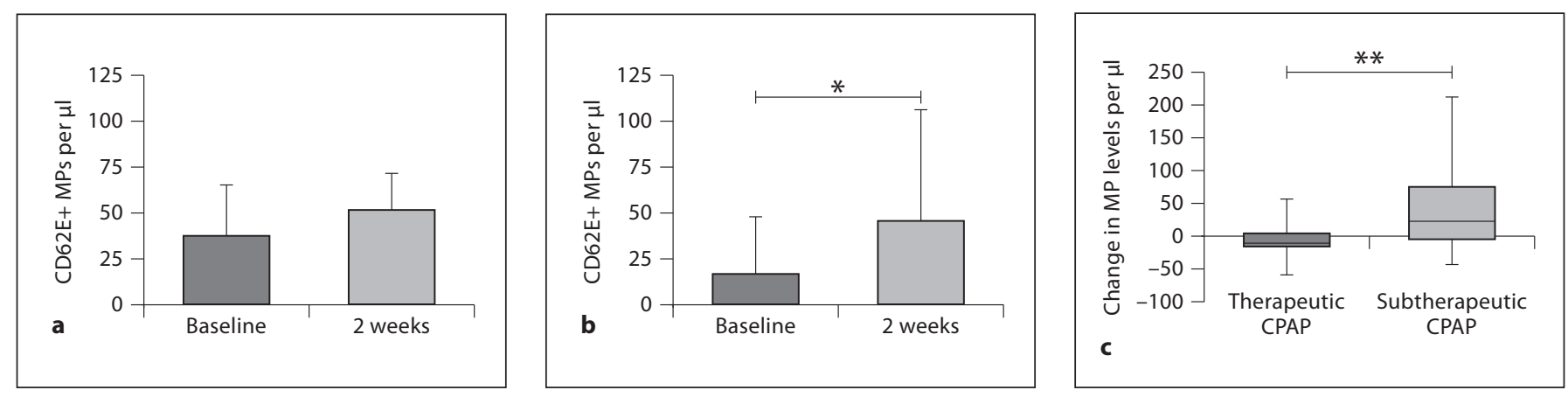

Fig. 2. Median (IQR) levels of CD62E+ EMPs in OSA patients receiving either therapeutic (a) or subtherapeutic CPAP (b). In the subtherapeutic group there was a significant increase in CD62E+ EMPs $\left({ }^{*} \mathrm{p}=0.040\right)$ between baseline and 2 weeks not seen in the therapeutic group. c Median (box: IQR, whiskers: range) change in CD62E+ EMPs between baseline and 2 weeks. There was a significant difference $\left({ }^{* *} \mathrm{p}=0.010\right)$ between the change in MP levels in the therapeutic and subtherapeutic groups.
Fig. 3. Median (IQR) levels of CD106+ EMPs in OSA patients receiving either therapeutic (a) or subtherapeutic CPAP (b). In the subtherapeutic group there was a significant increase in CD106+ EMPs $\left({ }^{* *} \mathrm{p}=0.007\right)$ between baseline and 2 weeks not seen in the therapeutic group.

Fig. 4. Median (IQR) levels of CD66B+ granulocyte-derived MPs in OSA patients receiving either therapeutic (a) or subtherapeutic CPAP (b). In the subtherapeutic group there was a significant increase in $\mathrm{CD} 66 \mathrm{~B}+$ granulocyte-derived MPs $\left({ }^{*} \mathrm{p}=\right.$ 0.029 ) between baseline and 2 weeks not seen in the therapeutic group.
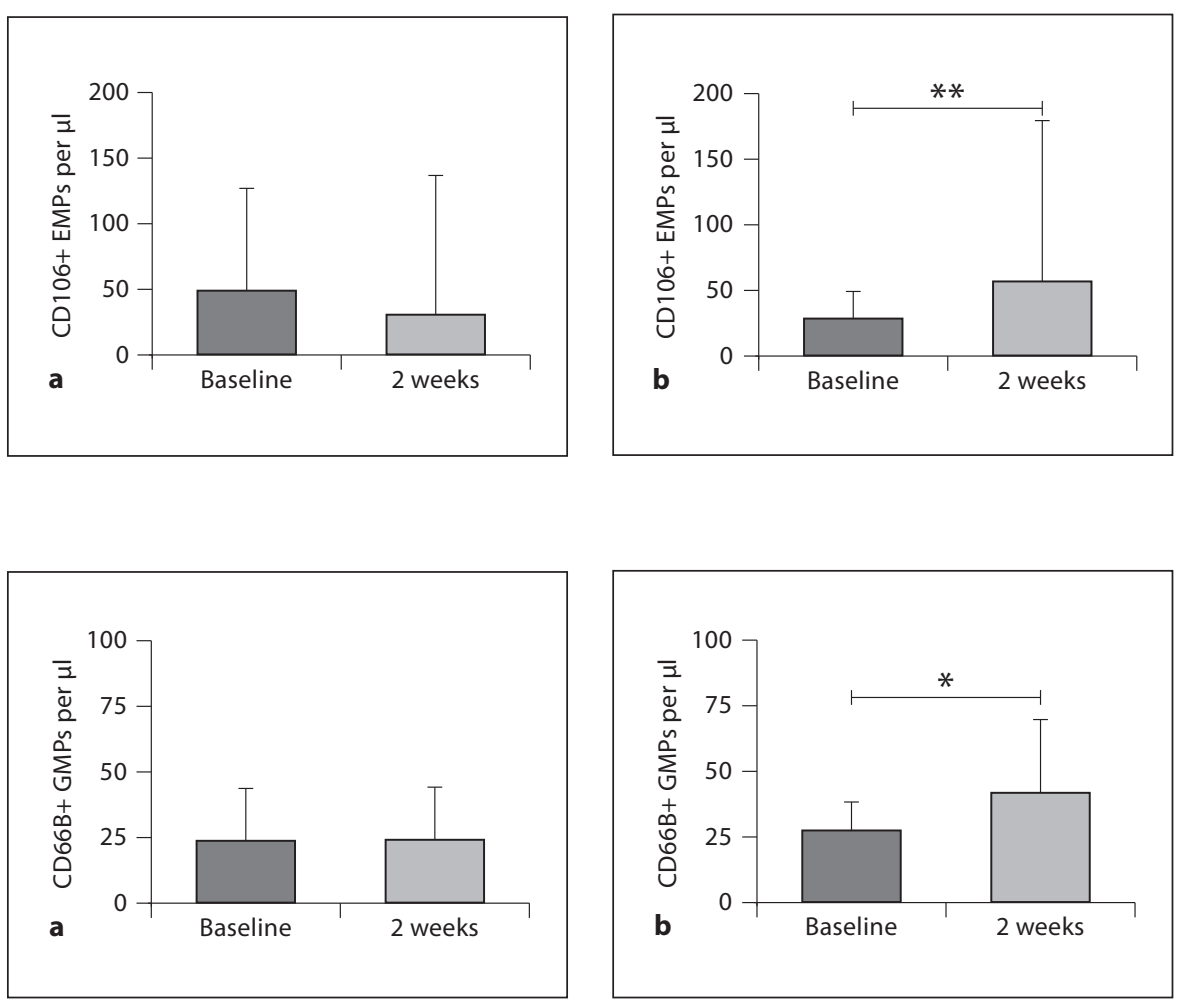

CD62E+ EMPs was applied. There was no significant difference in the change in CD106+ EMPs levels (median difference in change +21.9 per $\mu \mathrm{l} ; 95 \% \mathrm{CI}-4.7$ to +166.0 per $\mu l, p=0.105$ ) between the therapeutic and subtherapeutic groups. Withdrawal of CPAP therapy did not significantly change the number of CD31+CD41- EMPs (median difference in change -7.86 per $\mu$ l; 95\% CI -22.9 to +10.8 per $\mu l, \mathrm{p}=0.327$ ) (table 3 ).

\section{Granulocyte-Derived MPs (CD66B+)}

Withdrawal of CPAP therapy was associated with a significant increase in the number of $\mathrm{CD} 66 \mathrm{~B}+$ granulocytederived MPs $(\mathrm{p}=0.029)$ not seen in the therapeutic CPAP group (fig. 4). There was no significant difference in the change in $\mathrm{CD} 66 \mathrm{~B}+\mathrm{MP}$ levels between the therapeutic and subtherapeutic groups (median difference in change +16.3 per $\mu \mathrm{l}$; $95 \% \mathrm{CI}-5.3$ to +43.8 per $\mu \mathrm{l}, \mathrm{p}=0.132)($ table 3$)$. 
Table 3. Effect of CPAP withdrawal on MP levels

\begin{tabular}{|c|c|c|c|c|c|c|}
\hline & \multicolumn{2}{|l|}{ Baseline } & \multicolumn{2}{|l|}{ Change from baseline } & \multirow{2}{*}{$\begin{array}{l}95 \% \text { CI } \\
\text { between } \\
\text { groups }\end{array}$} & \multirow{2}{*}{$\begin{array}{l}\mathrm{p} \\
\text { value }\end{array}$} \\
\hline & $\begin{array}{l}\text { therapeutic } \\
\text { CPAP }(n=20)\end{array}$ & $\begin{array}{l}\text { subtherapeutic } \\
\text { CPAP }(\mathrm{n}=18)\end{array}$ & $\begin{array}{l}\text { therapeutic } \\
\text { CPAP }(n=20)\end{array}$ & $\begin{array}{l}\text { subtherapeutic } \\
\text { CPAP }(\mathrm{n}=18)\end{array}$ & & \\
\hline CD62E+ EMPs & $36.8(10.3$ to 65.3$)$ & $16.2(8.9$ to 47.6$)$ & $+1.7(-16.4$ to 8.7$)$ & $+21.5(-6.2$ to 72.1$)$ & +7.3 to +64.1 & $0.010^{*}$ \\
\hline CD106+ EMPs & $48.2(16.9$ to 125.8$)$ & $28.3(12.8$ to 49.3$)$ & $+2.7(-11.0$ to 60.9$)$ & $+20.9(0.6$ to 141.7$)$ & -4.7 to +166 & 0.105 \\
\hline CD31+CD41- EMPs & $64.2(49.0$ to 94.6$)$ & $69.3(17.5$ to 112.7$)$ & $-1.3(-28.9$ to 20.3$)$ & $+7.5(-18.3$ to 64.8$)$ & -22.9 to +10.8 & 0.327 \\
\hline CD66B+ granulocyte MPs & $23.8(14.4$ to 43.6$)$ & $27.0(16.5$ to 37.9$)$ & $+2.1(-21.4$ to 20.1$)$ & $+8.1(-4.7$ to 46.5$)$ & -5.3 to +43.8 & 0.132 \\
\hline CD45+ LMPs & $84.9(18.6$ to 160$)$ & $59.3(4.8$ to 200$)$ & $-1.3(-9.6$ to 28.7$)$ & $-5.2(-57.8$ to 10.0$)$ & -45.5 to +10.7 & 0.335 \\
\hline CD31+CD41+ PMPs & $530(322$ to 965$)$ & $534(370$ to 1561$)$ & $-75(-489$ to 205$)$ & $-8.5(-78.0$ to 690$)$ & -108 to +684 & 0.193 \\
\hline
\end{tabular}

Values are medians (IQR) per $\mu l .{ }^{*} \mathrm{p}<0.05$.

$\mathrm{p}$ values were calculated by a Mann-Whitney test of change from baseline between the therapeutic CPAP and subtherapeutic CPAP groups.

\section{Leukocyte-Derived MPs}

Withdrawal of CPAP therapy did not significantly change the number of CD45+ LMPs, and there was no significant difference in the change in levels between the two groups (median difference in change -19.8 per $\mu$; $95 \% \mathrm{CI}-45.5$ to +10.7 per $\mu \mathrm{l}, \mathrm{p}=0.335$ ) (table 3 ).

\section{Platelet-Derived MPs}

Withdrawal of CPAP therapy did not significantly change the number of PMPs, and there was no significant difference in the change in levels between the two groups (median difference in change +194 per $\mu$ l; 95\% CI -108 to +684 per $\mu \mathrm{l}, \mathrm{p}=0.193$ ) (table 3 ).

\section{Discussion}

To our knowledge this is the first report of a randomized controlled trial investigating the effects of CPAP therapy on the level of MPs. Withdrawal of CPAP therapy for 2 weeks was associated with a significant increase in EMP levels, providing evidence that MP formation may be causally linked to OSA and may promote endothelial activation in these patients.

Controlled trials have shown that OSA is an independent causal factor for hypertension, and a risk factor for other cardiovascular diseases [5, 21], even when controlling for other risk factors. The current opinion is that the consequences of OSA, including intermittent hypoxia and intrathoracic pressure changes and arousals, may result in inflammation, endothelial dysfunction, and ultimately arterial disease [7].

CPAP Withdrawal and Cell-Derived MPs
MPs may provide a linking mechanism between OSA and cardiovascular disease. EMPs appear to be both a cause and a consequence of endothelial dysfunction, and levels are correlated with other markers of endothelial dysfunction [22]. OSA is considered to represent a proinflammatory state, demonstrated by increased levels of pro-inflammatory proteins and cytokines $[23,24]$. MPs can be produced in response to inflammation and they have potent pro-inflammatory potential. They can promote leukocyte aggregation and binding of monocytes to endothelial cells, an early step in vascular inflammation [12]. MPs can also express phosphatidylserine and tissue factor, giving them thrombotic properties. Therefore, MPs have the potential to increase cardiovascular risk in OSA patients through endothelial dysfunction, inflammation, and thrombosis.

In the current trial, CD62E+ EMPs and CD106+ EMPs were both significantly increased from baseline to 2 weeks in the subtherapeutic group, and the change in CD62E+ EMP levels was significantly different between the therapeutic and the subtherapeutic groups. The baseline CD62E+ EMP levels were not identical between the two groups, as may be expected in a randomized study. However, the significant difference in the change in CD62E+ EMP levels between the therapeutic and subtherapeutic groups held true, even when a correction for the baseline levels was applied. CD31+CD41- did not significantly change over the 2 weeks in either patient group. It is recognized that subtypes of EMPs are formed by different mechanisms, and these subtypes express different markers. For example, CD62E+ EMPs are suggested to be markers of early endothelial cell activation, while raised numbers of CD31+CD41- EMPs are thought to reflect 
structural damage of endothelial cells [25]. Therefore, the findings of this study suggest that EMPs produced during cell activation are affected by CPAP therapy; however, those produced during cell death are not. We previously reported that EMPs were not elevated in a group of minimally symptomatic OSA patients compared to matched controls [14]; however, only CD31+CD41- EMPs were examined.

Yun et al. [16] reported significantly higher levels of EMPs in OSA than in matched controls and that EMPs were correlated with OSA severity. Following CPAP treatment, a significant reduction in CD62E+ EMPs, but not CD31+CD42- EMPs, was found. These findings were also corroborated by Jelic et al. [15], who reported elevated levels of EMPs in OSA patients and a trend towards decreased levels following CPAP, in a treatment uncontrolled study. CPAP treatment has previously been shown to improve endothelial function $[8,9]$, and indeed in the current trial a deterioration in endothelial function following CPAP therapy withdrawal was observed [18]. Therefore, the decrease in EMP levels with CPAP therapy may be an underlying mechanism of endothelial function improvement. However, it is remains unclear whether EMPs are a cause or a consequence of endothelial dysfunction. This uncertainty will need to be addressed in future studies.

Withdrawal of CPAP therapy was associated with a significant increase in the number of granulocyte-derived MPs. However, there was no significant difference in the change in levels between groups. Priou et al. [26] found that granulocyte-derived MPs were increased in OSA patients, with an ODI of $\geq 10$ events per hour. Polymorphonuclear cells have an enhanced readiness to respond with superoxide generation in OSA, which is reversed by CPAP treatment [27]. Therefore, it may be expected that granulocyte-derived MPs, a marker of polymorphonuclear cell activation, would be significantly elevated following withdrawal from CPAP.

Withdrawal of CPAP therapy was not associated with a significant change in the number of LMPs in the current study, even though LMPs have previously been shown to be elevated in OSA [14]. An explanation for this unexpected finding may be that 2 weeks of CPAP withdrawal was not long enough to cause a significant increase in LMPs.

PMP levels have also previously been shown to be elevated in patients with minimally symptomatic OSA [14]. Thus it may be expected that a treatment which significantly improves the pathophysiological consequences and symptoms of OSA may also reduce the levels of PMPs.
However, levels of PMPs were not significantly changed from baseline over the 2 weeks in either patient group. It may be the case that 2 weeks of treatment withdrawal is not sufficient to increase the levels of PMPs.

\section{Limitations}

We cannot exclude that a longer CPAP withdrawal period would be associated with more pronounced changes in MP levels; however, because of ethical issues, it may be difficult to prolong the intervention time. Short-term CPAP withdrawal may also have an exaggerated detrimental effect, as OSA patients on therapy may lose adaptive mechanisms to cope with endothelial damage. While flow cytometry is a commonly used method for MP analysis, it cannot be used to detect MPs smaller than $300 \mathrm{~nm}$ in diameter $[28,29]$, depending on the threshold of the machine.

\section{Conclusions}

This is the first randomized controlled trial to assess the impact of CPAP therapy withdrawal on MP levels. Withdrawal of CPAP therapy for 2 weeks was associated with a significant increase in EMPs. These results provide evidence that MP formation may be causally linked to OSA and may promote endothelial activation in these patients.

\section{Acknowledgments}

This report is independent research arising from a Healthcare Scientist Research Fellowship supported by the National Institute for Health Research and the Chief Scientific Officer. The views expressed in this publication are those of the authors and not necessarily those of the NHS, the National Institute of Health Research, or the Department of Health.

This study was supported by a grant of the Swiss National Science Foundation (32003B_124915) and the Swiss Society of Pneumology. The research was also partly supported by the National Institute for Health Research, Oxford Biomedical Research Centre. 


\section{References}

1 Young T, Peppard PE, Gottlieb DJ: Epidemiology of obstructive sleep apnea: a population health perspective. Am J Respir Crit Care Med 2002;165:1217-1239.

-2 Patil SP, Schneider H, Schwartz AR, Smith PL: Adult obstructive sleep apnea: pathophysiology and diagnosis. Chest 2007;132: 325-337.

3 Peker Y, Hedner J, Norum J, Kraiczi H, Carlson J: Increased incidence of cardiovascular disease in middle-aged men with obstructive sleep apnea: a 7-year follow-up. Am J Respir Crit Care Med 2002;166:159-165.

4 Peppard PE, Young T, Palta M, Skatrud J: Prospective study of the association between sleep-disordered breathing and hypertension. N Engl J Med 2000;342:1378-1384.

-5 Marin JM, Carrizo SJ, Vicente E, Agusti AG: Long-term cardiovascular outcomes in men with obstructive sleep apnoea-hypopnoea with or without treatment with continuous positive airway pressure: an observational study. Lancet 2005;365:1046-1053.

6 Redline S, Yenokyan G, Gottlieb DJ, Shahar E, O'Connor GT, Resnick HE, Diener-West M, Sanders MH, Wolf PA, Geraghty EM, Ali T, Lebowitz M, Punjabi NM: Obstructive sleep apnea-hypopnea and incident stroke: the sleep heart health study. Am J Respir Crit Care Med 2010;182:269-277.

-7 Kohler M, Stradling JR: Mechanisms of vascular damage in obstructive sleep apnea. Nat Rev Cardiol 2010;7:677-685.

8 Ip MS, Tse HF, Lam B, Tsang KW, Lam WK: Endothelial function in obstructive sleep apnea and response to treatment. Am J Respir Crit Care Med 2004;169:348-353.

-9 Cross MD, Mills NL, Al-Abri M, Riha R, Vennelle M, Mackay TW, Newby DE, Douglas NJ: Continuous positive airway pressure improves vascular function in obstructive sleep apnoea/hypopnoea syndrome: a randomised controlled trial. Thorax 2008;63: 578-583.

10 Buchner NJ, Quack I, Woznowski M, Stahle C, Wenzel U, Rump LC: Microvascular endothelial dysfunction in obstructive sleep apnea is caused by oxidative stress and improved by continuous positive airway pressure therapy. Respiration 2011;82:409-417.
11 Galetke W, Puzzo L, Priegnitz C, Anduleit N, Randerath WJ: Long-term therapy with continuous positive airway pressure in obstructive sleep apnea: adherence, side effects and predictors of withdrawal - a 'real-life' study. Respiration 2011;82:155-161.

12 VanWijk MJ, VanBavel E, Sturk A, Nieuwland R: Microparticles in cardiovascular diseases. Cardiovasc Res 2003;59:277-287.

13 Chironi G, Simon A, Hugel B, Del Pino M, Gariepy J, Freyssinet JM, Tedgui A: Circulating leukocyte-derived microparticles predict subclinical atherosclerosis burden in asymptomatic subjects. Arterioscler Thromb Vasc Biol 2006;26:2775-2780.

14 Ayers L, Ferry B, Craig S, Nicoll D, Stradling JR, Kohler M: Circulating cell-derived microparticles in patients with minimally symptomatic obstructive sleep apnoea. Eur Respir J 2009;33:574-580.

15 Jelic S, Lederer DJ, Adams T, Padeletti M, Colombo PC, Factor P, Le Jemtel TH: Endothelial repair capacity and apoptosis are inversely related in obstructive sleep apnea. Vasc Health Risk Manag 2009;5:909-920.

16 Yun CH, Jung KH, Chu K, Kim SH, Ji KH, Park HK, Kim HC, Lee ST, Lee SK, Roh JK: Increased circulating endothelial microparticles and carotid atherosclerosis in obstructive sleep apnea. J Clin Neurol 2010;6:89-98.

17 Kim J, Bhattacharjee R, Kheirandish-Gozal L, Spruyt K, Gozal D: Circulating microparticles in children with sleep disordered breathing. Chest 2011;140:408-417.

18 Kohler M, Stoewhas AC, Ayers L, Senn O, Bloch KE, Russi EW, Stradling JR: The effects of CPAP therapy withdrawal in patients with obstructive sleep apnea: a randomised controlled trial. Am J Respir Crit Care Med 2011;184:1192-1199.

19 Pepperell JC, Ramdassingh-Dow S, Crosthwaite N, Mullins R, Jenkinson C, Stradling JR, Davies RJ: Ambulatory blood pressure after therapeutic and subtherapeutic nasal continuous positive airway pressure for obstructive sleep apnoea: a randomised parallel trial. Lancet 2002;359:204-210.

20 Johns MW: A new method for measuring daytime sleepiness: the Epworth sleepiness scale. Sleep 1991;14:540-545.
21 Haentjens P, Van Meerhaeghe A, Moscariello A, De Weerdt S, Poppe K, Dupont A, Velkeniers B: The impact of continuous positive airway pressure on blood pressure in patients with obstructive sleep apnea syndrome: evidence from a meta-analysis of placebo-controlled randomized trials. Arch Intern Med 2007;167:757-764.

-22 Amabile N, Guerin AP, Leroyer A, Mallat Z, Nguyen C, Boddaert J, London GM, Tedgui A, Boulanger CM: Circulating endothelial microparticles are associated with vascular dysfunction in patients with end-stage renal failure. J Am Soc Nephrol 2005;16:33813388.

23 Gozal D, Kheirandish-Gozal L: Cardiovascular morbidity in obstructive sleep apnea: oxidative stress, inflammation, and much more. Am J Respir Crit Care Med 2008;177: 369-375.

24 Budhiraja R, Parthasarathy S, Quan SF: Endothelial dysfunction in obstructive sleep apnea. J Clin Sleep Med 2007;3:409-415.

25 Amabile N, Heiss C, Real WM, Minasi P, McGlothlin D, Rame EJ, Grossman W, De Marco T, Yeghiazarians Y: Circulating endothelial microparticle levels predict hemodynamic severity of pulmonary hypertension. Am J Respir Crit Care Med 2008;177:12681275.

26 Priou P, Gagnadoux F, Tesse A, Mastronardi ML, Agouni A, Meslier N, Racineux JL, Martinez MC, Trzepizur W, Andriantsitohaina $\mathrm{R}$ : Endothelial dysfunction and circulating microparticles from patients with obstructive sleep apnea. Am J Pathol 2010;177:974983.

27 Schulz R, Mahmoudi S, Hattar K, Sibelius U, Olschewski H, Mayer K, Seeger W, Grimminger F: Enhanced release of superoxide from polymorphonuclear neutrophils in obstructive sleep apnea: impact of continuous positive airway pressure therapy. Am J Respir Crit Care Med 2000;162:566-570.

28 Ardoin SP, Shanahan JC, Pisetsky DS: The role of microparticles in inflammation and thrombosis. Scand J Immunol 2007;66:159165 .

29 Beyer C, Pisetsky DS: The role of microparticles in the pathogenesis of rheumatic diseases. Nat Rev Rheumatol 2010;6:21-29. 